\title{
OÜRICÚRI
}

\section{A ECOSOFIA E A RELAÇÃO ENTRE HOMEM E NATUREZA NA SOCIEDADE MODERNA}

\author{
Kellison Lima CAVALCANTE ${ }^{*}$ \\ ${ }^{1}$ Licenciado em Filosofia (UFPI), Mestre em Tecnologia Ambiental (ITEP) e Doutorando em Educação \\ (UFBA). Instituto Federal de Educação, Ciência e Tecnologia do Sertão Pernambucano (IF Sertão-PE), \\ Petrolina-PE. *Autor Correspondente: E-mail: kellison.cavalcante@ifsertao-pe.edu.br \\ Recebido: 30.12.2019 Aceito: 21.12.2020 \\ https://doi.org/10.29327/ouricuri.10.1-9
}

Resumo: Entre suas funções, a Filosofia nos permite compreender a realidade e, diante das questões ambientais da atualidade, a Ecosofia consiste no estudo da relação entre a natureza e os seres humanos, propondo discussões entre meio ambiente, homem e relações sociais na modernidade. Esse trabalho tem como objetivo refletir sobre a relação do homem com o meio ambiente através dos princípios da Ecosofia. A Ecosofia proposta por Guattari (2009) aborda a nossa compreensão, como parte do meio em que vivemos, e como aprendemos e agimos sobre a problemática ambiental, tendo por base as três ecologias: a do meio ambiente, a das relações sociais e a da subjetividade humana (mental). Assim, é possível compreender que a Ecosofia é mais que uma reflexão sobre ecologia, natureza e relação homem-natureza, é uma busca por ações concretas, levando em consideração a interação do homem com o meio ambiente. Dessa forma, a Ecosofia estimula uma ampla consciência ambiental, possibilitando extrair do campo da aprendizagem e do conhecimento o potencial de nos tornarmos capazes de compreender o que 0 nosso planeta precisa e rever nossas ações.

Palavras-chave: Filosofia; Ecologia; Humanidade.

\section{ECOSOPHY AND THE RELATIONSHIP BETWEEN MAN AND NATURE IN MODERN SOCIETY}

Abstract: Among its functions, Philosophy allows us to understand reality and, given the current environmental issues, Ecosophy consists in the study of the relationship between nature and human beings, proposing discussions between environment, man and social relations in modernity. This work aims to reflect on the relationship between man and the environment through the principles of Ecosophy. The Ecosophy proposed by Guattari (2009) addresses our understanding as part of the environment in which we live, and how we learn and act on environmental issues, based on the three ecologies: the environment, social relations and the environment. human (mental) subjectivity. Thus, it is possible to understand that the Ecosophy is more than a reflection on ecology, nature and man-nature relationship, it is a search for concrete actions, taking into consideration the interaction between man and the environment. In this way, Ecosophy stimulates a broad environmental awareness, making it possible to extract from the field of learning and knowledge the potential to become able to understand what our planet needs and to review our actions.

Keywords: Philosophy, Ecology; Humanity.

\section{ECOSOFÍA Y LA RELACIÓN ENTRE EL HOMBRE Y LA NATURALEZA EN LA SOCIEDAD MODERNA}

Resumen: Entre sus funciones, la Filosofía nos permite comprender la realidad y, frente a los problemas ambientales actuales, la Ecosofía consiste en el estudio de la relación entre la 
naturaleza y los seres humanos, proponiendo discusiones entre el medio ambiente, el hombre y las relaciones sociales en la modernidad. Este trabajo tiene como objetivo reflexionar sobre la relación entre el hombre y el medio ambiente a través de los principios de la Ecosofía. La Ecosofía propuesta por Guattari (2009) aborda nuestra comprensión como parte del medio ambiente en el que vivimos y cómo aprendemos y actuamos sobre los problemas ambientales, en función de las tres ecologías: el medio ambiente, las relaciones sociales y el medio ambiente. subjetividad humana (mental). Por lo tanto, es posible comprender que la Ecosofía Ambiental es más que una reflexión sobre la ecología, la naturaleza y la relación hombre-naturaleza, es una búsqueda de acciones concretas, teniendo en cuenta la interacción entre el hombre y el medio ambiente. De esta manera, Ecosophy estimula una amplia conciencia ambiental, haciendo posible extraer del campo del aprendizaje y el conocimiento el potencial para poder comprender lo que nuestro planeta necesita y revisar nuestras acciones.

Palabras clave: Filosofía; Ecología; Humanidad.

\section{INTRODUÇÃO}

No processo evolutivo da espécie humana, o homem disputava os alimentos e o espaço com os animais, como forma de sobrevivência e demarcação de territórios. Porém, com o tempo marcou-se o desenvolvimento de habilidades relacionadas à racionalidade do homem, como a criação e uso de ferramentas para conseguir alimento e dominar o espaço. Nos primórdios da existência, o homem retirava da natureza apenas o essencial para o seu sustento sem interferir de forma agressiva no ecossistema.

No entanto, num determinado período da história, o homem começa a dominar a natureza e a maneira de manejar os recursos naturais vem sendo modificada a cada geração. Assim, a agricultura e a pecuária são resultadas do desenvolvimento das habilidades do homem e das maneiras de manejar os recursos naturais, como parte do processo de dominação da natureza na Antiguidade, tendo como resultado um processo de mudança na relação entre homem-natureza, desencadeando uma relação desigual e de mudança significativa no ambiente em que estamos inseridos.

A sedentarização do homem no campo e as transformações do ambiente durante o Neolítico provocaram a busca e a disseminação de conhecimento necessário para a compreensão da relação do homem com a natureza na sociedade moderna. Dessa forma, a discussão proposta nesse trabalho proporciona a construção de novos saberes socioambientais e ecológicos, e, sobretudo da condição humana na modernidade. O enfoque de discussão entre sociedade e natureza na perspectiva da co-evolução mitigará inovações e conhecimentos para as relações sociais e ambientais, como o reconhecimento da relação entre o homem e a natureza para um manejo e desenho de um desenvolvimento sustentável, em seus princípios ambientais e sociais.

Dessa forma, a Ecosofia consiste mais do que apenas uma Filosofia da Ecologia e sim um modo de pensar a destruição da natureza e das relações humanas na sociedade contemporânea. Assim, a Filosofia, através da consciência da deterioração do meio ambiente e das relações sociais, insere o homem na concepção da realidade que vivencia, procurando respostas e soluções para os problemas que identifica. Propõe analisar a humanidade de forma integradora do 
meio em que vive através da articulação prática do cotidiano do homem.

A Ecosofia tem como finalidade proporcionar uma discussão sobre a relação do homem com a natureza, enfatizando a formação de um novo ser humano, com base nas três ecologias. Dessa maneira, o pensamento ecosófico possibilita a reflexão e a compreensão do desenvolvimento de novas práticas sociais e analíticas na busca da criação de novas subjetividades, tornando o homem como um ser capaz de interagir com o meio ambiente. Essa reflexão subsidia o aprofundamento das normas éticas e premissas sociais da ação humana no meio ambiente.

A Ecosofia se configura como uma necessidade social, criando uma conscientização de que todos devem cuidar e preservar o meio ambiente para as futuras gerações, formando indivíduos atuantes. A Ecosofia torna o homem participante nas discussões e no debate das questões ambientais e nas suas soluções. Nessa perspectiva, esse trabalho tem como objetivo refletir sobre a relação do homem com o meio ambiente através dos princípios da Ecosofia de Félix Guattari, principalmente na contribuição do pensamento filosófico.

\section{MATERIAL E MÉTODOS}

A pesquisa se fundamenta no método dialético com foco na abordagem da formação humana nos fundamentos da Ecosofia. Utilizou-se uma abordagem explicativa, bem como de caráter bibliográfico, no sentido do liame entre a relação do homem e a natureza no processo de conscientização ecológica, a partir de uma pesquisa bibliográfica.

Gil (2008) ressalta que a pesquisa bibliográfica parte dos estudos exploratórios na busca de ampliar e fundamentar a análise do tema em discussão, com a realização de pesquisas desenvolvidas a partir da técnica de análise de conteúdo. Dessa forma, as fontes secundárias foram obtidas através de consultas em bases de dados disponibilizadas no Portal Periódicos Capes, como SciELO, Scopus e Google Acadêmico, através dos indexadores de ecosofia, ecologia profunda e ecologia humana. Para a análise e discussão, a pesquisa baseou-se nas técnicas de investigação e redação filosófica propostas por Cunha (2013), que destaca a leitura analógica e analítica de textos filosóficos.

Assim, a pesquisa bibliográfica foi realizada para apresentar uma discussão sobre as três ecologias propostas no pensamento ecosófico, que são a ecologia mental, a ecologia social e a ecologia ambiental. Dessa forma, a abordagem explicativa trouxe argumentos da revisão de literatura para compreensão da relação entre o homem e a natureza.

\section{DISCUSSÕES A PARTIR DA ECOSOFIA}

De acordo com Guattari (2009), vivemos no planeta sob a aceleração das mutações técnico-científicas e do desenvolvimento insustentável ocasionado pela ação antrópica no meio ambiente, que nos distanciam de nossas relações pessoais, sociais e ambientais. Diante dos 
novos padrões e modos de vida do homem, potencializamos o uso indiscriminado dos recursos naturais, sem a preocupação de que estes são recursos finitos.

Conforme Guattari (2009) as intensas transformações na natureza a partir da Revolução Industrial engendram os fenômenos de desequilíbrios ambientais e que paralelamente influenciam os modos de vida do homem do campo, que evoluem no sentido de uma progressiva deterioração. Dessa forma, a capacidade de desenvolvimento do pensamento racional e crítico da problemática em sua totalidade e conjunto oportunizam remediar as implicações futuras da existência humana e do meio ambiente, estabelecendo processos de desenvolvimento territorial. Assim, Guattari (2009) desenvolveu a teoria da Ecosofia, a partir da Ecologia Profunda de Arne Naess, que consiste na articulação entre os três registros ecológicos (o da subjetividade humana, o das relações sociais e o do meio ambiente) para esclarecer a problemática ambiental.

Dessa forma, a Ecosofia consiste mais do que apenas uma Filosofia da Ecologia e sim um modo de pensar a destruição da natureza e das relações do homem na sociedade contemporânea. Assim, através da consciência da deterioração do meio ambiente e das relações sociais, insere o homem na concepção da realidade que vivencia, procurando respostas e soluções para os problemas que identifica. Propõe analisar o homem de forma integradora no meio em que vive através da articulação da sua individualidade, da socialização e do meio ambiente.

Segundo Avila-Pires (1983) de um mero elo nos ecossistemas naturais, como um grande predador, o homem passou a influir decisivamente sobre o ambiente e adquiriu o poder de alterar os processos naturais, inclusive aqueles que regulam sua própria evolução. Nessa perspectiva, Maffesoli (2010) destaca que, com a abrangência das discussões da problemática ambiental em função de uma atitude filosófica, o homem passa a viver em um momento de transição de predador da natureza para aquele que deseja conviver em harmonia com ela. Assim, o homem procura construir soluções para a sua relação com o meio ambiente, deixando de ser o centro dela para um olhar mais amplo. Para Maffesoli (2017), a Ecosofia consiste em uma mudança de paradigma, onde o homem tem a consciência que é parte indissociável do meio ambiente.

\section{A Ecosofia Mental}

A Ecosofia Mental implica compreender a essência da individualização do ser através da sua subjetividade. Para isso, a Ecosofia Mental nos permite refletir inicialmente sobre a oposição entre o sujeito e a sociedade que cobra cada vez mais a obrigatoriedade hierárquica e a dominação do ser. Dessa forma, é possível o pensamento crítico sobre o inconsciente da mentalidade do homem atual na formação da sua subjetividade através da irrupção dos valores históricos, da contribuição maquínica nos valores da sociedade e aspectos ambientais que juntos se relacionam para formação da subjetividade humana.

De acordo com Guattari (2009) a subjetividade humana encontra-se difundida nos 
questionamentos do império de um mercado mundial de consumo estimulado pelo Capitalismo Mundial Integrado e pelo conjunto produtivo da revolução maquínica do mundo pós-moderno. problema, segundo Guattari (2006) é que o desenvolvimento da subjetividade humana é influenciado de forma direta e impactante de maneira maquínica, apontando como causa da segregação social do indivíduo, uma verdadeira caosmose ${ }^{1}$ do cotidiano do ser. Dessa forma, o pensamento ecosófico constata as segregações e as hierarquizações, tornando-o classificatório em posições subjetivas e classes.

O problema da individualização do homem, provocado pelas segregações e hierarquizações, está no princípio da convivência em grupo e coletividade. Essa convivência estabelece o sentido da inserção social do indivíduo e o seu pertencimento ao grupo. Para isso, Guattari (2009) destaca que:

No seio dos países desenvolvidos reencontramos esse mesmo princípio de tensão social e de "estimulação" pelo desespero, com a instauração de regiões crônicas de desemprego e da marginalização de uma parcela cada vez maior de populações de jovens, de pessoas idosas, de trabalhadores "assalariados", desvalorizados etc. (Guattari, 2009, p. 12).

Esses agravamentos sociais contemporâneos são resultados de falta de uma significação da individualidade do homem, corrompido pelas forças do poder Capitalista Mundial Integrado e pela falta de conhecimento. Assim, de acordo com Guattari (2009) a Ecosofia Mental tem a capacidade de analisar criticamente a introjeção do poder repressivo por parte dos oprimidos.

Nesse sentido, Guattari (2009) procura investigar uma ressingularização do indivíduo através da Ecosofia mental que segundo o filósofo:

\begin{abstract}
A ecosofia mental, por sua vez, será levada a reinventar a relação do sujeito com o corpo, com o fantasma, com o tempo que passa, com os "mistérios" da vida e da morte. Ela será levada a procurar antídotos para a uniformização midiática e telemática, o conformismo das modas, as manipulações da opinião pela publicidade, pelas sondagens, etc. (Guattari, 2009, p. 16).
\end{abstract}

As mutações pós-modernas, as revoluções informática e maquínica transformaram o modo de viver e ser da humanidade, trazendo limites para o desenvolvimento individual da subjetividade. Assim, a Ecosofia mental resulta no processo de subjetivação do indivíduo, a sua psyché, não como um ser patológico, mas a relação mental singular de cada indivíduo com as problemáticas coletivas. A partir dessa relação, o pensamento ecosófico procura relacionar a problemática em geral do ser, do social e da natureza.

Seja na vida individual ou na vida coletiva, o impacto de uma ecologia mental não

\footnotetext{
1 Termo conceituado por Guattari para expressar um novo paradigma estético da relação catastrófica da sociedade contemporânea, retratando a complexidade social (Guattari, 2006).
} 
pressupõe uma importação de conceitos e de práticas a partir de um domínio "psi" especializado. Fazer face à lógica da ambivalência desejante, onde quer que ela se perfile - na cultura, na vida cotidiana, no trabalho, no esporte etc. -, reapreciar a finalidade do trabalho e das atividades humanas em função de critérios diferentes daqueles do rendimento e do lucro: tais imperativos da ecologia mental convocam uma mobilização apropriada do conjunto dos indivíduos e dos segmentos sociais. (Guattari, 2009, pp. 40-41).

A Ecosofia mental procura explicar de forma racional e lógica o espaço íntimo de cada indivíduo, a partir do conhecimento de seu próprio inconsciente, sua existência e suas opiniões, ou seja, o seu mundo interior, que se relaciona com as exterioridades do mundo social, o mundo externo. A articulação da Ecosofia Mental contribui para singularidade na formação de cada indivíduo, mesmo que sofrendo influências das mutações contemporâneas, possibilitando a construção e ressignificação na relação com as crenças, os valores sociais e ambientais. Demonstra-se a necessidade de considerar o homem em seu mundo interno, a partir de sua vivência, emoções e sentidos, carregados de rupturas de relações com o seu ser e com o social.

Dessa forma, a Ecosofia Mental propõe a sensibilização e conhecimento da individualidade do homem no seu cotidiano individual, familiar, profissional e social. Para Guattari (2009) a Ecosofia Mental tem como objetivo a produção singular da existência do homem. Assim, a subjetividade humana prepara o homem contra os acontecimentos e fatos sociais que perturbem a relação do homem consigo mesmo, com a sociedade e com o meio ambiente.

Conforme Guattari (2009) a questão da Ecosofia Mental pode surgir a qualquer momento, em todos os lugares, para além dos conjuntos bem constituídos na ordem individual ou coletiva. Isso é uma grande constatação para os desequilíbrios individuais do ser que não se encontra inserido em um contexto de construção e autoconstrução na sociedade e no meio em que vive. Constatando assim, a eficácia estético-existencial da Ecosofia mental. Dessa forma, Guattari (2009) ressalta que Ecosofia mental deveria ser julgada em função de:

1) sua capacidade de circunscrever as cadeias discursivas em ruptura de sentido; 2) sua possibilidade de operar conceitos autorizando uma autoconstrutibilidade teórica e prática. $\mathrm{O}$ freudismo responde bem ou mal à primeira exigência, mas não à segunda; inversamente, o pós-sistemismo teria antes tendência a responder à segunda, ao mesmo tempo em que subestimaria a primeira; já no campo políticosocial, os meios "alternativos" geralmente desconhecem o conjunto das problemáticas relativas à ecologia mental (Guattari, 2009, p. 40).

Na proposição da Ecosofia mental, o indivíduo tem a capacidade de autoconstrução do ser e de sua existência, rompendo as semióticas do capitalismo regente dos modos de vida contemporâneos. Nesse sentido, é possível estruturar fatos e reorganizar o dissenso entre a produção através do uso indiscriminado dos recursos naturais e da existência humana e suas relações sociais.

Guattari (2006) sugere uma reconstrução da dimensão do indivíduo como centro dos acontecimentos e a localização da subjetividade do ser como agente atuante nas escolhas éticas 
do mundo. Assim, a Ecosofia mental não individualiza o ser em sua subjetividade, mas o coloca de forma coletiva na problemática ambiental atual, como um processo primário de singularização.

\title{
A Ecosofia Social
}

As mutações do mundo contemporâneo desvelam através das grandes catástrofes resultantes das ações do homem o processo de desconstrução da identidade do ser e de sua vida em sociedade. Assim, a subjetivação de cada indivíduo nos mostra cada vez mais a destruição da vida em comum em sociedade e a transitoriedade e a desterritorialidade do convívio em grupos. Dessa forma, o pensamento de Guattari (2009) corrobora para o entendimento de que se valoriza o mundo da produção capitalista, onde o principal problema consiste nas ações do homem na sociedade contemporânea, que extrai recursos da natureza sem compreender que são finitos.

Nesse sentido, para compreender todos os sistemas comunicacionais que geram essas divergências na sociedade, Guattari (2009) reagrupou quatro principais regimes semióticos que regram o Capitalismo Mundial Integrado, a saber:

\begin{abstract}
a) as semióticas econômicas (instrumentos monetários, financeiros, contábeis, de decisão...); b) as semióticas jurídicas (título de propriedade, legislação e regulamentações diversas...); c) as semióticas técnico-científicas (planos, diagramas, programas, estudos, pesquisas...); d) as semióticas de subjetivação, das quais algumas coincidem com as que acabam de ser enumeradas mas conviria acrescentar muitas outras, tais como aquelas relativas à arquitetura, ao urbanismo, aos equipamentos coletivos etc. (p. 31).
\end{abstract}

Para a compreensão desses regimes, a Ecosofia Social consiste na atitude filosófica do indivíduo e as relações do socius com todos os elementos e instrumentos semióticos que compõem a trajetória das mutações da contemporaneidade. Assim, conforme Guattari (2009) a questão será literalmente reconstruir o conjunto das modalidades do ser em grupo, ressignificando as relações da subjetividade do homem com a sua própria exterioridade.

Dessa forma, a relação desses elementos do Capitalismo Mundial Integrado resulta, segundo Guattari (2009), nas causas materiais, formais, finais e eficientes da destruição do homem em sociedade. Atrelado a todo esse sistema semiótico, a subjetividade do homem tem efeito direto sobre as mutações e as adversidades do mundo em sociedade. Assim, a Ecosofia Social tem como propósito reaver as relações humanas na sua essência em grupo e coletiva.

De acordo com Guattari (2009) a Ecosofia Social não resulta apenas em recomendações gerais, mas o desenvolvimento de práticas efetivas de experimentação tanto nos níveis microssociais quanto em escalas institucionais maiores. Consiste na permanente construção da essência humana na descoberta das verdades do mundo e da sua própria existência, mas também na proposta de resultar efeitos e atitudes na sociedade.

A ecosofia social consistirá, portanto, em desenvolver práticas específicas que 
tendam a modificar e a reinventar maneiras de ser no seio do casal, da família, do contexto urbano, do trabalho etc. Certamente seria inconcebível pretender retornar a fórmulas anteriores, correspondentes a períodos nos quais, ao mesmo tempo, a densidade demográfica era mais fraca e a densidade das relações sociais mais forte que hoje (Guattari, 2009, pp. 15-16).

A atitude filosófica, através da Ecosofia Social, permite pensar as relações sociais na perspectiva da heterogeneidade do homem provocada pelos avanços e retrocessos do mundo contemporâneo. Para Guattari (2015), as diferenças da heterogênese não podem se destruir, e sim se hetero-alimentar. Essa proposta deve ser o poder de reaproximar a subjetividade do homem com o sentido de viver em sociedade, compreender o outro próximo e o distante. Assim, Guattari (2015) ressaltou que não se pode olhar apenas para um ou outro lado, mas para todos os lados, para uma totalidade maior.

Essa totalidade maior consiste no entrelace proposto pela Ecosofia, em sua completude com a subjetividade do homem e suas relações com a sociedade e a natureza. Para esse entendimento, Guattari (2009) afirma que o problema das relações sociais se originou do distanciamento do homem da sua cultura, que permitia a vida social através do reconhecimento de sua identidade e pertencimento aquela sociedade. A ecologia social deverá trabalhar na reconstrução das relações humanas em todos os níveis do socius (Guattari, 2009, p. 33).

A reconstrução das relações humanas deve permitir o desenvolvimento do homem como um ser analítico e crítico, capaz de mensurar o poder de suas ações em destruir ou reedificar as condições da existência humana em sociedade. Como pensaram Deleuze e Guattari (2003), o importante é o meio, e não o início ou o fim. Pois essa nova maneira de se pensar e agir em sociedade tem a oportunidade de criar novas sínteses das relações humanas, respeitando a heterogeneidade.

No entanto, o hibridismo social contemporâneo retalha os sistemas multipolares, como a oposição descrita por Guattari (2009) entre o Terceiro Mundo e o Mundo Desenvolvido e suas multifacetadas distorções. Essa dualidade de desconstrução e desterritorialidade do indivíduo provoca questões como as imigrações, os refugiados, a discriminação de gênero, o racismo e tantos outros temas emergentes da nossa sociedade que ainda prioriza as disjunções. Como vimos na exploração do trabalho escravo na História do mundo e nos refugiados de guerras, e que ainda podemos constatar a explosão racista no Brasil, mesmo 130 anos após a promulgação da Lei Áurea ${ }^{2}$, e a imigração venezuelana no Brasil, refugiando-se da desconstrução da sua nacionalidade. Ou ainda na migração latina à América do Norte e Europa, ou da cultura quilombola e indígena para uma sociedade maquínica e tecnológica, bem como o respeito à binaridade e à não-binaridade dos gêneros.

Essas lutas de classes exacerbam o pensamento social, provocando o distanciamento, a

\footnotetext{
2 Lei Imperial $n^{\circ} 3.353$, sancionada em 13 de maio de 1888, que extinguiu a escravidão no Brasil (FAUSTO, 2007).
} 
diferenciação e a não aceitação do ser em grupo. Dessa forma, Guattari (2009) ressalta que o habitat humano sofreu severas mutações provenientes das revoluções informáticas, robóticas, do desenvolvimento do gênio genético e da mundialização do conjunto dos mercados. Essas mutações provocaram a aceleração e evolução das sociedades, resultando na interdependência do ser com a máquina e com o tecnológico, tornando disjuntivas as próprias relações sociais e tratando a natureza como um produto de mercado do Capitalismo Mundial Integrado.

Ainda nesse contexto, Guattari (2009) reflete sobre as relações de gênero, especialmente a relação homem-mulher, que segundo o filósofo, a condição feminina está longe de ter melhorado ao longo do tempo. A subordinação da mulher ao homem nas relações afetivas e profissionais ainda são vistas na atualidade, provocando a fragilidade da condição feminina diante do homem, desencadeando rupturas e desigualdades sociais. Porém, a Ecosofia Social nos remete à ascensão da subjetividade e revolução feminina ao longo dos tempos, provocadas pelas lutas dos movimentos feministas que alçaram objetivos cada vez mais contemplativos na condição da mulher na decisão dos seus próprios caminhos e progressões profissionais. Dessa forma, a relação homem-mulher ganha cada vez mais o sentido de respeito às diferenças de gêneros.

Ainda que a independência sexual das mulheres, relacionada com a disponibilidade dos meios de contracepção e aborto, tenha crescido de forma bastante irregular, ainda que o crescimento dos integrismos religiosos não cesse de gerar uma minoração de seu estado, alguns indícios levam a pensar que transformações de longa duração - no sentido de Fernand Braudel - estão de fato em curso (designação de mulheres para chefia de Estado, reivindicação de paridade homem-mulher nas instancias representativas etc) (Guattari, 2009, pp. 13-14)

Nesse contexto, na sociedade contemporânea, a mulher consolida seu espaço profissional e a sua independência da imposição histórica masculina nas relações. Essa consolidação resulta na aceitação das decisões tomadas, formas de agir e sua importância no contexto familiar, profissional, político e social. Colocando a mulher no espaço de valorização do ser e das relações de igualdade e de respeito. O processo de subjetivação do ser na relação homem-mulher entrelaça os papéis sociais, sem diferenciar gêneros.

Essa problemática do gênero sofre contornos mais indissociáveis nas relações em grupo, como a homofobia e o preconceito na relação gênero e sexualidade na atualidade. A Ecosofia Social busca aproximar as diferenças tão ignoradas ao longo do processo de identidade nas relações de gênero.

Ao abordar a valorização do gênero, sem a distinção arcaica, na sociedade contemporânea, Guattari (2009) destaca como desafio a exploração do trabalho infanto-juvenil, comparando-a aos piores períodos do Século XIX. Dessa forma, as relações sociais da juventude são dominadas pelas mutações, provocando a dependência dos recursos tecnológicos e a fragilidade no aspecto do uso da racionalidade na resolução de questões e problemas do convívio 
em grupo.

A juventude, embora esmagada nas relações econômicas dominantes que the conferem um lugar cada vez mais precário, e mentalmente manipulada pela produção de subjetividade coletiva da mídia, nem por isso deixa de desenvolver suas próprias distâncias de singularização com relação à subjetividade normalizada. A esse respeito, o caráter transnacional da cultura rock e absolutamente significativo: ela desempenha o papel de uma espécie de culto iniciático que confere uma pseudo-identidade cultural a massas consideráveis de jovens, permitindo-lhes constituir um mínimo de Territórios existenciais (Guattari, 2009, p. 14).

As transformações no sentido de conhecimento sobre cultura retardam a evolução social do ser humano, estimulando as ideologias arcaicas de separação social que culminam no agravamento da violência generalizada, da dependência química, do esfacelamento familiar, da discriminação de classes, do preconceito de gênero, do racismo étnico e das desigualdades sociais. Esse retardamento resulta nas rupturas sociais que agravam as crises da subjetividade humana, das relações sociais e ambientais na contemporaneidade. Dessa forma, a Ecosofia Social reflete sobre toda a coletividade do ser em grupo, proporcionando oportunizar a aprendizagem e convivência com o novo e inovador, advindos das constantes mutações do mundo.

No entanto, para Guattari (2009) toda a problemática social, tem como princípio as formas de transmissão e produção do conhecimento, revelada pelos limites do poder técnico-científico da humanidade. Porém, esse limite é imposto, ainda, pelo Capitalismo Mundial Integrado, que vê apenas o lucro, expondo a sociedade aos riscos do desenvolvimento desgovernado da economia do poder.

Chernobyl e a Aids nos revelaram brutalmente os limites dos poderes técnicocientíficos da humanidade e as "marchas-à-ré" que a "natureza" nos pode reservar. É evidente que uma responsabilidade e uma gestão mais coletivas se impõem para orientar as ciências e as técnicas em direção a finalidades mais humanas. Não podemos nos deixar guiar cegamente pelos tecnocratas dos aparelhos de Estado para controlar as evoluções e conjurar os riscos nesses domínios, regidos no essencial pelos princípios da economia de lucro (Guattari, 2009, p. 24).

Dessa forma, o conhecimento limitado e controlado pelo desenvolvimento técnico-científico tende a colaborar para a dependência social, fragilizando as relações. A partir dessa limitação resulta-se em fatos sociais como a desigualdade econômica, os privilégios políticos e comumente e devastador as discriminações racial e cultural, como observamos em um processo de estratificação social.

Guattari (2009) destaca que o princípio particular à Ecosofia Social diz respeito à promoção de um investimento afetivo e pragmático nos grupos humanos, como uma forma de inserção do homem em sociedade, resgatando sua subjetividade e identidade social. Assim, possibilita a reconstrução das relações no convívio social, valorizando a subjetividade do ser. Para

Revista Ouricuri, Juazeiro, Bahia, v.10, n.1. p.001-019. jan./jul., 2020.

http://www.revistas.uneb.br/index.php/ouricuri | ISSN 2317-0131 
isso, Guattari (2009) ressalta que para fazer face aos destroços do Capitalismo Mundial Integrado se faz necessária uma imensa reconstrução das engrenagens sociais. Nesse sentido, a Ecosofia Social oportuniza a união da sociedade em uma única forma de convivência: o respeito ao próximo.

\section{A Ecosofia Ambiental}

As constantes mutações do mundo contemporâneo, provocando as múltiplas formas da subjetivação do homem e as fragilidades heterogêneas das relações sociais, torna essencial o pensamento sobre as questões e problemáticas ambientais em escala planetária. A partir dessas mutações, a atitude filosófica tem como finalidade conectar os elementos de constituição do ser e o desenvolvimento de práticas específicas que comuniquem os avanços tecnológicos, científicos e culturais para a preservação da natureza.

Com as metamorfoses da psyché e do socius na contemporaneidade, a natureza auferiu uma forma maquínica, como um produto do Capitalismo Mundial Integrado para o avanço tecnológico da humanidade. Assim, para Guattari (2009) o princípio da Ecosofia Ambiental é de que tudo nela é possível, tanto o pior como o melhor. De modo irracional, tanto as piores catástrofes são possíveis, como o caso de Chernobyl retratado pelo filósofo, como os acontecimentos de apropriações de encostas de montanhas, que em períodos chuvosos correm riscos de desmoronamento. Como também são possíveis as evoluções flexíveis do homem, que usa o conhecimento e a sabedoria para melhorar o mundo em que vive, como o uso do que a natureza nos oferece em fontes renováveis e sem a destruição do nosso habitat natural, com as energias oriundas da luz e do calor solar, do movimento das marés e da força dos ventos.

Nesse sentido, Guattari (2009) desenvolve o sentido da eco-lógica na apropriação da lógica das intensidades dos processos evolutivos da humanidade nos problemas do meio ambiente. Assim, a eco-lógica, como uma atitude filosófica, racional e crítica das situações da contemporaneidade, consiste na busca de conhecimento e ação sobre os movimentos e processos de evolução, que resultam na degradação do Planeta.

Dessa forma, para Guattari (2009) a Ecosofia Ambiental objetiva a articulação de novas práticas ecológicas. Essas novas práticas ecológicas devem tornar progressivas e atuantes as singularidades subjetivas da humanidade, passando para o pensamento coletivo, no bem estar do grupo. Assim, a heterogeneidade tem a capacidade de organização e articulação do funcionamento do sistema global.

Para isso, Guattari (2009) afirma que:

Em cada foco existencial parcial as práxis ecológicas se esforçarão por detectar os vetores potenciais de subjetivação e de singularização. Em geral trata-se de algo que se coloca atravessado à ordem "normal" das coisas - uma repetição contrariante, um dado intensivo que apela outras intensidades a fim de compor outras configurações existenciais. Tais vetores dissidentes se encontram 
relativamente destituídos de suas funções de denotação e de significação, para operar enquanto materiais existenciais descorporificados (p. 28).

Nessa atitude filosófica, os objetivos comuns para preservação e conservação do meio ambiente serão de todos, em um movimento coletivo de interesse global diante de problemáticas que emergem da postura individualista do ser e da competição social que marginaliza o ser em grupo. Nesse contexto, Guattari (2009) explica que haverá momentos de ressingularização onde as subjetividades individuais e coletivas se manifestarão em busca de soluções para a problemática ambiental. Onde, justamente, a Ecosofia Ambiental despertará o caráter filosófico do uso da razão, procurando dirimir escolhas na produção e assimilação de perspectivas mais seguras para o meio ambiente. O que se faz evidente é a proposta articuladora da subjetividade do ser individual e da valorização das relações sociais na construção de um ambiente natural propício para uma relação harmoniosa entre o homem e a natureza.

Em minha opinião, a ecologia ambiental, tal como existe hoje, não fez senão iniciar e prefigurar a ecologia generalizada que aqui preconizo e que terá por finalidade descentrar radicalmente as lutas sociais e as maneiras de assumir a própria psique. Os movimentos ecológicos atuais têm certamente muitos méritos, mas, penso que na verdade, a questão ecosófica global é importante demais para ser deixada a algumas de suas correntes arcaizantes e folclorizantes, que às vezes optam deliberadamente por recusar todo e qualquer engajamento político em grande escala. A conotação da ecologia deveria deixar de ser vinculada à imagem de uma pequena minoria de amantes da natureza ou de especialistas diplomados. Ela põe em causa o conjunto da subjetividade e das formações de poder capitalísticos - os quais não estão de modo algum seguros que continuarão a vencê-la, como foi o caso na última década (Guattari, 2009, p. 36).

A partir de então, a Ecosofia Ambiental despertará o engajamento e uma articulação eminente na crise ambiental avassaladora atual. Crise que se apropria desde a singularização do homem em sua individualidade, que toma conta da fragilização das relações sociais e emana na apropriação e utilização inadequada do nosso habitat natural. Como a própria raiz "eco", utilizada na eco-lógica de Guattari (2009) para representar o nosso habitat e meio natural de viver e conviver em sociedade e como parte integrante e constituinte da natureza.

Diante dos paradoxos instaurados pelo distanciamento do homem em sua essência, provocados pelo capitalismo moderno, pela desculturalização e desterritorialização, a Ecosofia Ambiental e a sua articulação eco-lógica têm potencial para reequilibrar a problemática ambiental dominante. De acordo com Guattari (2009), torna-se fundamental falar da desterritorialização selvagem do Terceiro Mundo, que afeta concomitantemente a textura cultural das populações, o hábitat, as defesas imunológicas, o clima etc. De fato, a evolução e as constantes mutações da sociedade provocaram um desequilíbrio generalizado, que precisa de uma articulação éticopolítica através dos registros da Ecosofia.

Tratar-se-á antes de movimento de múltiplas faces dando lugar a instâncias e

Revista Ouricuri, Juazeiro, Bahia, v.10, n.1. p.001-019. jan./jul., 2020.

http://www.revistas.uneb.br/index.php/ouricuri | ISSN 2317-0131 
dispositivos ao mesmo tempo analíticos e produtores de subjetividade. Subjetividade tanto individual quanto coletiva, transbordando por todos os lados as circunscrições individuais, "egoisadas", enclausuradas em identificações, e abrindo-se em todas as direções: do lado do socius, mas também dos Phylum maquínicos, dos Universos de referência técnico-científicos, dos mundos estéticos, e ainda do lado de novas apreensões "pré-pessoais" do tempo, do corpo, do sexo... Subjetividade da ressingularização capaz de receber cara-a-cara o encontro com a finitude sob a forma do desejo, da dor, da morte... Todo um rumor me diz que nada disso se dá por si mesmo (Guattari, 2009, p. 54)!

Dessa forma, a partir do encontro das subjetividades individual e coletiva podemos refletir pelo uso da eco-lógica que as condições do meio ambiente não podem ser dissociadas da nossa condição de existência no Planeta. Essa condição está associada diretamente a nossa parte como integrantes do meio ambiente, nosso habitat, a nossa formação como um sujeito ambientalmente consciente.

Conforme Guattari (2009), a natureza não pode ser separada da cultura e precisamos aprender a pensar "transversalmente" as interações entre ecossistemas, mecanosfera e Universos de referência sociais e individuais. Assim, a Ecosofia Ambiental e os seus demais registros priorizam concernir às relações de uma ética ambiental e ações efetivas na preservação do meio ambiente.

\section{Uma Articulação Ecosófica na Contemporaneidade}

Para Habermas (2012) a Filosofia empenha-se desde o começo para explicar o mundo como um todo, como uma unidade na diversidade dos fenômenos. Em busca dessa totalidade, Châtelet (1994) ressalta que a busca filosófica progride em direção à racionalidade. Nesse sentido, para Hessen (1987) a Filosofia se desenvolve pela orientação para a totalidade dos objetos e para o caráter racional dessa orientação. Diante desse desenvolvimento do uso da racionalidade para explicar a totalidade, Avila-Pires (1983) ressalta que o homem ocupa uma posição singular no mundo, como um ser inteligente que construiu uma civilização tecnológica, apanágio de sua evolução cultural.

Assim, tomando a evolução do homem, a Ecosofia desenvolve-se a partir da atitude filosófica da totalidade das problemáticas contemporâneas, mediante o uso da racionalidade. Não apenas como uma Filosofia da Ecologia, mas como uma postura ativa da condição humana sobre o meio ambiente e das relações sociais, na unicidade da relação do pensamento. Segundo AvilaPires (1983) de um mero elo nos ecossistemas naturais, como um grande predador, o homem passou a influir decisivamente sobre o ambiente e adquiriu o poder de alterar os processos naturais, inclusive aqueles que regulam sua própria evolução.

Nesse sentido, Avila-Pires (1983) afirma que:

Ao contrário do que se diz, o homem não é o único animal capaz de destruir o ambiente, mas é o único capaz de preservá-lo. O progresso não compromete, necessariamente, o grau de qualidade de vida ou o equilíbrio dos ecossistemas: 
os conhecimentos que traz podem ser utilizados em um sentido ou em outro. Estão nas mãos do homem tecnológico as soluções para os problemas que vem criando. Depende de sua própria vontade adotá-las, ou não (p. 150).

Dessa forma, toda a evolução cultural, tecnológica e científica coloca o homem em uma posição de agente modificador, capaz de inferir com soluções para a problemática ambiental em desequilíbrio. Para Avila-Pires (1983) o homem é parte integrante da biosfera e é o único organismo capaz de compreendê-la.

Diante desse pensamento, Boff (2004) ressalta que:

\begin{abstract}
O ser humano e a sociedade sempre estabelecem uma relação com o meio ambiente. O ser humano provém de um longo processo biológico. Sem os elementos da natureza, da qual ele é parte e parcela, sem os vírus, as bactérias, os microorganismos, o código genético, os elementos químicos primordiais, ele não existiria. As sociedades sempre organizam suas relações para com o meio no sentido de garantir a produção e reprodução da vida. [...] O estado do mundo está ligado ao estado de nossa mente. Se o mundo está doente é indício de que nossa psique também está doente. Há agressões contra a natureza e vontade de dominação porque dentro do ser humano funcionam visões, arquétipos, emoções que levam a exclusões e a violências (pp. 20-21).
\end{abstract}

Porém, essa relação do homem e da sociedade com a natureza é observada pela organização econômica e política da contemporaneidade, interferindo em todo o processo de produção de significados do ser no mundo. Assim, Boff (2004) destaca a importância de um novo paradigma para a comunidade planetária, capaz de emergir uma nova forma de dialogação com a totalidade dos seres e de suas relações.

Para Boff (2004) esse novo paradigma procura discernir a questão fundamental da crise atual que consiste na crise da civilização hegemônica. Dessa forma, a preocupação da ecologia profunda de Boff (2004) volta-se para o paradigma dominante da nossa sociedade dos modelos de relações mais determinantes. Assim, busca-se um sentido de diálogo e de discernimento das questões fundamentais para a sobrevivência e preservação da natureza.

De acordo com Dodsworth-Magnavita (2012), a Ecosofia tem a capacidade de sintetizar a preocupação da Filosofia Contemporânea com as questões ambientais. Assim, DodsworthMagnavita (2012) afirma que:

Inicialmente, podemos pensar que Ecosofia é um termo cuja emergência vem suprir a carência de uma expressão capaz de sintetizar a preocupação filosófica relativamente recente com as questões ecológicas. Entretanto, é mais do que uma filosofia da ecologia (ou uma "Ecofilosofia"). Na Ecosofia, não somos "amigos da sabedoria do ambiente". A exemplo dos antigos gimnosofistas hindus, a sabedoria é buscada no corpo, nos sentidos, em uma relação fisiológica com a natureza, não exigindo, portanto, grande erudição, mas sim atenção ao ambiente. E prioriza, sobretudo, uma existência focalizada no necessário, combatendo os supérfluos ( $p$. 16).

O conceito de Ecosofia expressa as formas como os sujeitos interagem entre si e com o

Revista Ouricuri, Juazeiro, Bahia, v.10, n.1. p.001-019. jan./jul., 2020.

http://www.revistas.uneb.br/index.php/ouricuri | ISSN 2317-0131 
meio ambiente, a partir do conhecimento de práticas ambientais sustentáveis no processo de inclusão do sujeito no meio ambiente e como parte da natureza, para preservação e conscientização ambiental. Assim, a Ecosofia busca aproximar uma relação harmoniosa entre o ambiente e o homem, deixando a característica de ser dominante do homem para o ser capaz de agir na resolução da degradação ambiental.

Boff (2004) afirma que a missão do ser humano não é a dominação da natureza, mas o cuidado dela, pois ele é parte responsável de toda a comunidade do Planeta. Assim, conforme Dodsworth-Magnavita (2012), a Ecosofia consiste em uma postura ativista e política que objetiva agir no mundo, mais do que simplesmente pensá-lo. Tal como Gallo (2008) ressalta a importância de ações efetivas na sociedade pós-industrial e na cultura pós-moderna em constante mutação. Essa ação advém do pensamento sobre a natureza, no aspecto da procura do entendimento da relação do homem com o seu habitat.

De acordo com Gonçalves (2008), a prática ecosófica aproxima o homem de si mesmo, do outro e da natureza. O enfoque está na necessidade de entendermos e aprendermos sobre a problemática ambiental, sobre as ações que a causaram e suas implicações ou projeções ao longo do tempo. Assim, a atitude ecosófica ressalta a importância do homem na totalidade de suas relações sociais e individuais, que sintetizam sua relação com o meio em que vive.

Gonçalves (2008) destaca que a Ecosofia promove um dilema na relação da subjetividade com a exterioridade e o social. Assim, põe em discussão a ação do homem no meio ambiente, seu modo de ser individual e social como integrante do mesmo ecossistema natural. Dessa forma, a Ecosofia consiste na atitude filosófica entre o equilíbrio do modo de viver contemporâneo e a relação com o meio ambiente, como parte indissociável que somos.

Para Guattari (2009), a Ecosofia e o enlace dos registros ecológicos não servem apenas para englobar todas as abordagens ecológicas heterogêneas em uma mesma ideologia totalizante, mas para nos mostrar o contrário, uma perspectiva ético-política da diversidade. Assim, a Ecosofia busca ressaltar a heterogeneidade da humanidade a partir das diferenças e distintas instâncias da subjetividade do homem. Dessa forma, Hur (2015) corrobora para o entendimento de que para pensar a subjetividade relacionada à sua exterioridade, somada à preocupação da gestão política e ambiental do planeta, deve-se trabalhar de forma articulada os três registros ecológicos.

Nesse sentido, Devall e Sessions (1985) formularam fundamentos aplicáveis ao pensamento ecosófico, baseando-se nas ideias de Arne Naess, precursor do Movimento da Ecologia Profunda. Os oito fundamentos, descritos por Devall e Sessions (1985) são:

1. O bem-estar e o florescimento da vida humana e da não-humana sobre a Terra têm valor em si próprios (sinônimos: valor intrínseco e valor inerente). Esses valores são independentes da utilidade do mundo não-humano para propósitos humanos. 2. A riqueza e a diversidade das formas de vida contribuem para a realização desses valores e são esses valores em si mesmas. 3. Os humanos não 
têm nenhum direito de reduzir essa riqueza e diversidade exceto para satisfazer necessidades humanas vitais. 4 . O florescimento da vida humana e das culturas é compatível com uma substancial diminuição na população humana. $O$ florescimento da vida não-humana exige essa diminuição. 5. A interferência humana atual no mundo não-humano é excessiva, e a situação está piorando rapidamente. 6. As políticas precisam ser mudadas. Essas políticas afetam estruturas econômicas, tecnológicas e ideológicas básicas. $O$ estado de coisas resultante será profundamente diferente do atual. 7. A mudança ideológica é basicamente a de apreciar a qualidade de vida (manter-se em situações de valor intrínseco), não a de adesão a um sempre crescente padrão de vida. Haverá uma profunda consciência da diferença entre grande e importante. 8. Aqueles que subscrevem os pontos precedentes têm a obrigação de tentar implementar, direta ou indiretamente, as mudanças necessárias (p. 49).

Os problemas ambientais são resultados da evolução da sociedade, em seus aspectos econômicos, políticos, sociais e culturais, que sintetizam a subjetividade da condição humana. Dessa forma, a observação dos fundamentos, baseados na Ecologia Profunda de Naess, colabora para o desenvolvimento racional e lógico do equilíbrio ecológico e da subjetividade humana. Essa subjetividade significa a nossa percepção sobre o mundo em que vivemos e sobre nós mesmos, nosso modo de pensar e agir para preservar e cuidar do meio ambiente.

Nessa perspectiva, Maffesoli (2010) destaca que, com a abrangência das discussões da problemática ambiental em função de uma atitude filosófica, o homem passa a viver em um momento de transição de predador da natureza para o que deseja conviver em harmonia e tomar uma atitude ecosófica. Assim, de acordo com o pensamento ecosófico, o homem procura soluções para a relação com o meio ambiente, deixando de ser o centro para um olhar mais amplo para todas as direções. Ainda de acordo com Maffesoli (2010), a Ecosofia consiste em uma mudança de paradigma, onde o homem tem a consciência que é parte indissociável do meio ambiente.

Maffesoli (2010) define a Ecosofia como uma forma de compreender a metamorfose em curso, que faz passar de progressismo para uma progressividade. Dessa forma, a Ecosofia contribui para a minimização de resultados degradantes do próprio homem, da sociedade e da natureza e a compreensão dos fundamentos dos sentimentos do homem e sua subjetividade, da vivência em grupo, dos territórios, da cultura e do meio ambiente.

Em vez de se lamentar, e consciente do vitalismo ambiente, é tempo de produzir um novo Discurso do Método, que seja um esclarecimento retrospectivo. Ou seja, que saiba retroceder do derivado ao essencial. Compreender o primeiro à luz do segundo. Assim será possível, em seu sentido etimológico e em seu sentido total, compreender a metamorfose em curso. Está nos fazendo passar de um progressismo (que foi potente, competitivo, mas que se tornou algo enfermiço) a uma progressividade que reinveste nos arcaísmos: povo, território, natureza, sentimentos, impulsos... que acreditáramos ultrapassar (Maffesoli, 2017, p. 1).

Para Maffesoli (2017) o progressismo moderno tem dificuldade em aceitar a progressividade natural. Nesse sentido, a Ecosofia desperta a capacidade de uma articulação 
prática entre identificar a metamorfose e mutações e agir em busca de um novo método de soluções e respostas. Para isso, a compreensão e o conhecimento tornam-se essenciais para um pensamento ecosófico que contemple a totalidade entre os três registros.

Maffesoli (2017) ressalta que o denominador comum entre a natureza e o social se torna manipulável, manobrável. Dessa forma, a capacidade da Ecosofia torna-se evidente no poder de controlar e possuir do homem. Para isso, todo o pensamento ecosófico evidencia-se, segundo Maffesoli (2017), no inconsciente coletivo moderno. A partir de uma reflexão dos fundamentos ecosóficos, o homem pode relacionar a sua individualização, a sua convivência social e a natureza e passa a preocupar-se com a devastação do mundo e de suas relações.

De acordo com Devall e Sessions (2004), o amor à sabedoria relaciona a ética, as normas, as regras e a prática, tornando a Ecosofia um deslocamento da ciência para a sabedoria ecológica, como uma atitude ético-política. Conforme Hernández (1998), a Ecosofia consiste em um novo nome para a filosofia política, como um grito diante da heterogeneidade e as caosmoses contemporâneas. Assim, o que precisamos no mundo contemporâneo é a expansão do pensamento ecológico em direção ao pensamento da Ecosofia. A condição humana passa a ser um ser integrado no meio, um ser completo, holístico, que conjuga aspectos biológicos, mentais, sociais e espirituais.

De acordo com Gallo (2003), o gênero humano desenvolve de tal modo sua consciência no tempo que chega um momento em que não basta sentir o mundo criando valores (mitos) sobre o mundo. Surge o desejo de descobrir as leis que regem o nosso mundo, a querer entender 0 mundo de modo racional e procurar soluções para os problemas resultantes de nossas ações. Nesse sentido, é possível destacar que a filosofia se opõe ao mito, pois a consciência filosófica não se limita a sentir o mundo. Assim a Ecosofia tem como finalidade interpretar de modo racional os questionamentos e problemas do nosso meio ambiente para, em seguida, questionar a realidade.

Nessa perspectiva, o pensamento ecosófico possibilita a relação do ser humano com a realidade que o produz e o atravessa, em suas múltiplas dimensões. Assim, através da compreensão das três ecologias torna-se imprescindível a nós, como seres humanos e parte indissociável do meio ambiente, a procura da conciliação dessa relação de possibilidade no nosso Planeta para minimizar os riscos de problemas ambientais e intervenções humanas na natureza.

\section{CONSIDERAÇÕES FINAIS}

De acordo com o pensamento filosófico de Félix Guattari, vivemos em uma Mecanosfera em constantes mutações técnico-científica e cultural que dominam nosso modo de viver no Planeta. Surgiu então, a necessidade de se compreender a complexidade da vida pós-moderna regida pelos avanços da globalização. Dessa forma, quando os problemas ambientais começaram a tornar-se prioridade no seio político e social contemporâneo, a Ecosofia proposta por Guattari 
procurou concatenar de forma lógica e racional o que a Filosofia poderia fazer pelo mundo e pela devastação do meio ambiente, como uma questão urgente.

Diante da crise ambiental no mundo pós-moderno e maquínico do capitalismo integrado, Guattari fundamentou-se no ativismo ecológico e político da Ecologia Profunda de Arne Naess na busca por uma Filosofia capaz de agir para minimizar o impacto da evolução humana sobre o meio ambiente. De sobremaneira, é possível observar sua inspiração pós-marxista como uma crítica ao paradigma antropocêntrico da natureza como um produto para o capitalismo e do homem desculturalizado e desterritorializado.

Para isso, a Ecosofia de Guattari propôs a observação, através de uma dimensão planetária e totalizante, das problemáticas contemporâneas, provocando uma verdadeira revolução política, social e cultural. Assim, a Ecosofia consiste na dimensão das relações do homem e da subjetividade humana (psyché), das relações sociais e da cultura (socius) e do meio ambiente (natureza), através das três ecologias: mental, social e ambiental. Dessa forma, buscase uma dimensão ecossistêmica dos registros ecosóficos através da atitude filosófica.

A Ecosofia se expressa como uma atitude filosófica através da reflexão crítica de um modo de coexistência e ressignificação entre o homem, a sociedade e a natureza. A partir desse pensamento o "natural" e o "cultural" surgem como entidades indissociáveis, trazendo a subjetividade humana, a multiplicidade social, o apoio aos direitos humanos e a diversidade ambiental como questões necessárias. Assim, é possível estabelecer como tudo se encontra interligado, desde a depressão, o suicídio, o racismo, a homofobia, o machismo, a violência e a degradação do meio ambiente. Todos os elementos se unificam em um agir filosófico para dirimir as antinomias entre o homem e a natureza.

O homem não se reconhece como parte indissociável da natureza e torna-a um produto de sua evolução, provocando grandes prejuízos ambientais e transformando a vida no nosso habitat natural de maneira desordenada. Assim, a Ecosofia Ambiental reúne a heterogeneidade das modificações antrópicas em busca da reparação das crises ambientais. Como podemos usar os avanços tecnológicos, através de uma conciliação mental e social, para a minimização dos impactos do aquecimento global. Desperta-se o engajamento da humanidade em uma articulação para a resolução e mitigação da problemática ambiental.

A Ecosofia se expressa como uma atitude filosófica através da reflexão crítica de um modo de coexistência e ressignificação entre o homem, a sociedade e a natureza. A partir desse pensamento o "natural" e o "cultural" surgem como entidades indissociáveis, trazendo a subjetividade humana, a multiplicidade social, o apoio aos direitos humanos e a diversidade ambiental como questões necessárias. Assim, é possível estabelecer como tudo se encontra interligado, desde a depressão, o suicídio, o racismo, a homofobia, o machismo, a violência e a degradação do meio ambiente. Todos os elementos se unificam em um agir filosófico para dirimir as antinomias entre o homem e a natureza. 


\section{REFERÊNCIAS}

Avila-Pires, F. D. Princípios de ecologia humana. Porto Alegre: Ed. da Universidade UFRGS/Brasília: CNPq, 1983.

Boff, L. Ecologia: grito da terra, grito dos pobres. Rio de Janeiro: Sextante, 2004.

Châtelet, F. Uma história da razão. Entrevistas com Émile Noël. Trad. Lucy Magalhães. Rio de Janeiro: Jorge Zahar Editor, 1994.

Cunha, J. A. Iniciação à investigação filosófica: um convite ao filosofar. 2. ed. Campinas-SP: Editora Alínea, 2013. 456 p.

Deleuze, G.; Guattari, F. Kafka: para uma literatura menor. Lisboa: Assírio e Alvim, 2003.

Devall, B.; Sessions, G. Deep ecology: living as if nature mattered. Salt Lake City: Gibbs Smith, 1985.

Devall, B.; Sessions, G. Ecologia profunda: dar prioridade à natureza na nossa vida. Águas Santas: Edições Sempre-em-Pé, 2004.

Dodsworth-Magnavita, A. A filosofia para questões urgentes. Filosofia Ciência e Vida, São Paulo, n. 72, p. 14-22, 2012.

Fausto, B. História do Brasil. São Paulo: Editora da Universidade de São Paulo, 2007.

Gallo, S. Deleuze e a educação. Belo Horizonte: Autêntica, 2003.

Gallo, S. Pesquisa em educação: o debate modernidade e pós modernidade. Pesquisa em Educação Ambiental, 3(1), 33-58, 2008.

Gil, A. C. Métodos e técnicas de pesquisa social. 6. ed. São Paulo: Atlas, 2008.

Gonçalves, E. C. A figura do professor de filosofia configurada na ecosofia. In: VIII Congresso Internacional de Filosofia, 2008, Caxias do Sul-RS. Anais... Caxias do Sul-RS: APF, 2008.

Guattari, F. ¿Qué es la ecosofía?: textos presentados y agenciados por Stéphane Nadaud. Ciudad Autónoma de Buenos Aires: Cactus, 2015.

Guattari, F. As três ecologias. 20. ed. Trad. Maria Cristina F. Bittencourt. Campinas: Papirus, 2009.

Guattari, F. Caosmose: um novo paradigma estético. 4aㅗ reimpressão. Rio de Janeiro: Editora 34, 2006.

Habermas, J. Teoria do agir comunicativo: racionalidade da ação e racionalidade social. Trad. Paulo Astor Soethe. São Paulo: Martins Fontes, 2012.

Hernández, E. Ecosofia: el nuevo nombre de la filosofia política. Nómadas, 5(1), 58-56, 1998.

Hessen, J. Teoria do conhecimento. 8. ed. Coimbra: Armênio Amado, 1987.

Hur, D. U. Guattari e a ecosofia. Psicologia Política, 15(33), 423-430, 2015.

Maffesoli, M. Ecosofia: sabedoria da casa comum. Revista Famecos mídia, cultura e tecnologia, 24(1), 2017. DOI: 10.15448/1980-3729.2017.1.24007.

Maffesoli, M. Saturação. São Paulo: Iluminuras, 2010. 